\title{
TRATAMENTO CIRÚRGICO DA METÁSTASE DE FEOCROMOCITOMA
}

\section{SURGICAL TREATMENT OF PHEOCHROMOCYTOMA METASTASIS}

\author{
Fábio Kanomata,ACBC-MS ${ }^{1}$ \\ Eduardo Linhares Riello de Mello, TCBC-RJ'² \\ José Humberto Simões Correa, TCBC-RJ ${ }^{3}$
}

\section{INTRODUÇÃO}

Feocromocitoma é uma doença rara. A vasta maioria é benigna e apresenta sintomas secundários à hipersecreção adrenérgica com manifestações clínicas exuberantes. A variedade maligna representa em torno de $10 \%$ dos casos e seu diagnóstico baseia-se na presença de metástases.

$\mathrm{O}$ tratamento inicial é a ressecção cirúrgica ${ }^{1,2}$. Em caso de recidiva local ou metastática a conduta é controversa. Os resultados com quimioterapia e radioterapia são pobres.

Relatamos um caso tratado de feocromocitoma com ressecção e que apresentou recidivas local e metastática submetidas a sucessivas ressecções com sucesso.

\section{RELATO DO CASO}

Mulher de 52 anos, apresentando dor abdominal, tumoração palpável em hipocôndrio direito e antecedente de hipertensão arterial. A tomografia de abdome constatou tumoração de supra-renal direita e pólo superior de rim direito apresentando compressão de veia cava inferior sem sinais de invasão (Figura 1).

Foram realizadas as seguintes dosagens: ácido vanil mandélico (AVM) em urina de 24 horas: 15,6mg ( normal; 1,5 a 9); dopamina sérica: 179 pg (normal: 25 a 50); epinefrina sérica: 1.473 (normal: 20 a 50) e norepinefrina sérica: $1.498 \mathrm{pg}$ (normal: 100 a 35). A cintigrafia com metaiodo benzil guanidina (MIBG) confirmou hipercaptação em topografia de supra-renal direita.

Foi submetida a laparotomia com ressecção da massa tumoral com aproximadamente $7 \mathrm{~cm}$ no maior diâmetro, posterior ao arco duodenal com crescimento à direita da veia cava inferior.
Manteve controle ambulatorial com dosagem de AVM no primeiro trimestre de seguimento de $2,6 \mathrm{mg} /$ urina de 24 horas e níveis pressóricos normais. O laudo histopatológico foi de feocromocitoma.

Aos 45 meses de seguimento, iniciou hipertensão arterial e elevação de AVM (13,4mg/urina de 24 horas). A cintigrafia com MIBG detectou hipercaptação em gradil costal direito e topografia de supra-renal direita (Figura 2). A tomografia revelou nódulo torácico em contiguidade com pleura e quarto arco costal direito e massa tumoral abdominal.

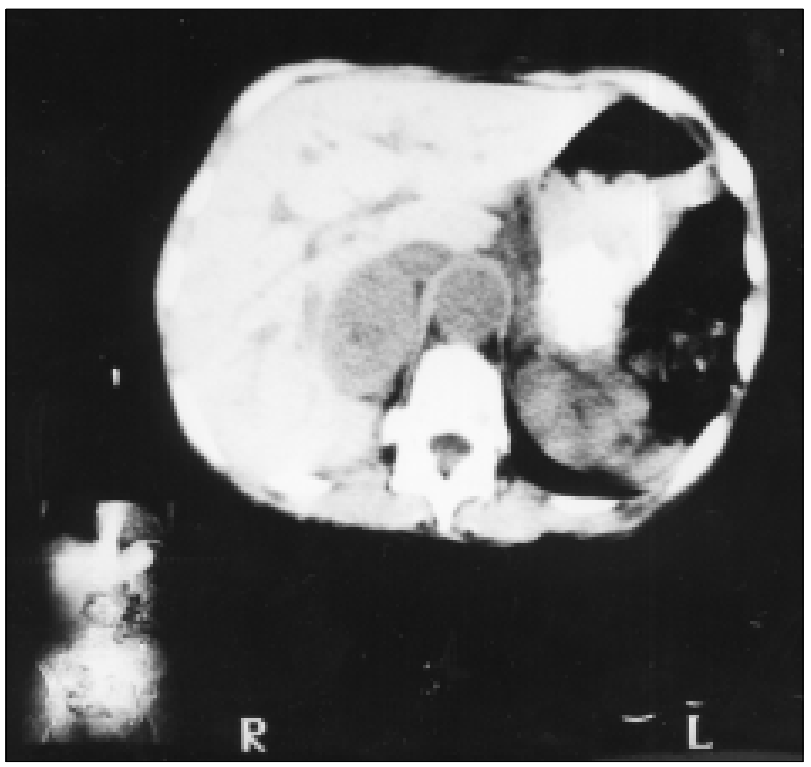

Figura 1 - Tomografia computadorizada de abdôme mostrando massa tumoral em topografia de glândula supra-renal direita.

1. Cirurgião Oncológico da Santa Casa de Campo Grande, MS. Ex-Residente da Seção de Cirurgia Abdominopélvica do Hospital do Câncer, INCA, Rio de Janeiro.

2. Chefe de Clínica da Seção de Cirurgia Abdominopélvica do Hospital do Câncer, INCA, Rio de Janeiro.

3. Chefe da Seção de Cirurgia Abdominopélvica do Hospital do Câncer, INCA, Rio de Janeiro.

Recebido em 03/05/2000

Aceito para publicação em 22/05/2001

Trabalho realizado na Seção de Cirurgia Abdominopélvica do Hospital do Câncer, Instituto Nacional de Câncer, Rio de Janeiro. 


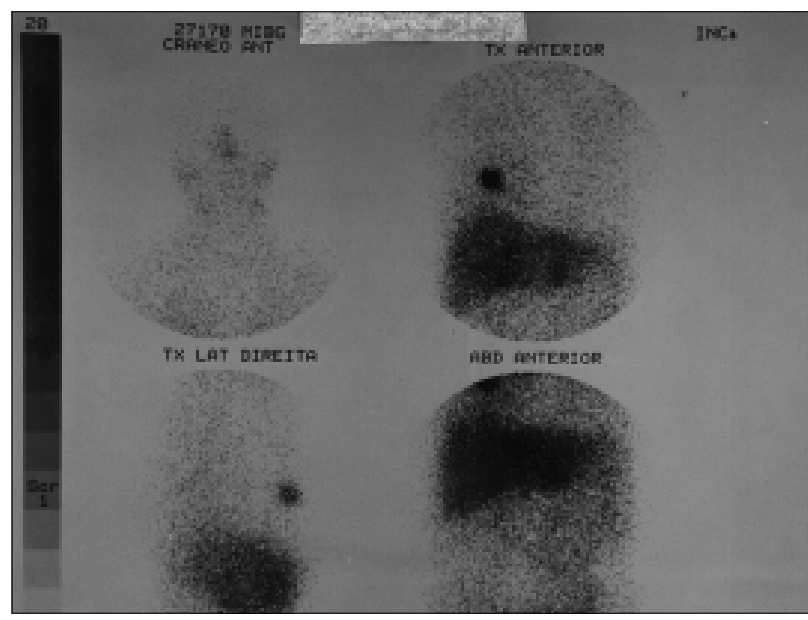

Figura 2-Cintigrafia com meta iodo benzil guanidina mostrando hiper-captações no gradil costal direito e loja supra-renal direita.

Nova laparotomia foi realizada com ressecção de tumoração de 4 x $3 \mathrm{~cm}$ em topografia retrocaval no nível da veia renal direita. O laudo histopatológico confirmou feocromocitoma.

Manteve quadro de hipertensão e AVM elevado, sendo encaminhada à cirurgia torácica, onde foi submetida a ressecção de segmento de arco costal direito na região anterior com $10 \mathrm{~cm}$ de extensão em monobloco com musculatura intercostal supra e subjacente e reconstrução com tela sintética. O laudo histopatológico confirmou feocromocitoma metastático.

Durante as três operações, a paciente apresentou crises hipertensivas graves decorrentes da manipulação tumoral, cujo controle foi dificil até a retirada da peça cirúrgica.

Até o sexto ano de controle ambulatorial desde a primeira intervenção, a paciente encontra-se com hipertensão arterial controlada, dosagens normais e cintigrafia com MIBG normal.

\section{DISCUSSÃO}

Feocromocitoma é uma efecção rara, principalmente a variante maligna (11\% a $19 \%$ de aproximadamente 400 novos casos por ano nos EUA - Brennan, 1982) ${ }^{1}$.

Entre os pacientes que têm a glândula ressecada devese considerar a possibilidade de recidiva ou doença residual. Neste caso, as recidivas tanto local como metastática causaram manifestações clássicas relacionadas à hipersecreção adrenérgica.

A abordagem da doença localizada é cirúrgica e convencionalmente realizada com laparotomia ampla.

A videolaparoscopia tem indicações específicas e muito embora dentre as cirurgias de supra-renal o feocromocitoma seja a que atinge maior morbidade, o número de complicações é baixo ${ }^{3}$. A sua prática já está estabelecida, sendo o limite máximo sugerido na literatura variável de 7 a $15 \mathrm{~cm}$ no maior diâmetro.

O tratamento da recidiva não está definido. A literatura é escassa. Considera-se que sejam radiorresistentes, muito embora haja relato isolado de controle em metástases cerebral e hepática ${ }^{4}$. O tratamento quimioterápico combinado (ciclofosfamida, vincristina e dacarbazina) tem valor discutível, tal qual a radioterapia.

O uso de iodoterapia (1311-MIBG) é considerado por alguns autores como a escolha inicial, seguido por quimioterapia em casos de doença de evolução rápida.

A abordagem cirúrgica de recidivas locais e metástases é a primeira escolha de acordo com Brennan et al. ${ }^{1} \mathrm{em}$ uma série de oito casos de pacientes submetidos a ressecção de feocromocitomas benignos e malignos. Tanto os casos de persistência de doença (residual) como recidiva local ou metastática tiveram beneficio em sobrevida, tendo sido realizados múltiplos tipos de ressecção.

Devido a sua lenta evolução e terapia não-cirúrgica pobre, o tratamento de doença recidivada ou residual é eminentemente cirúrgico. A raridade da afecção não permite séries largas. Neste caso em particular a paciente apresentou doença ressecável, porém é essencial o controle dos efeitos adrenérgicos graves com cuidados de monitoração e disponibilidade de drogas especificas no pré, per e pós-ope-ratório.

\begin{abstract}
The authors describe a case of a 52 years-old woman who presented recurrent and metastatic pheochromocytoma from a primary lesion ressected from the right adrenal, who was treated by surgical ressection with good results.
\end{abstract}

Key Words: Pheochromocytoma; Metastatic; Recurrent.

\title{
REFERÊNCIAS
}

1. Brennan, Murray F. Persistent and Recurrent Pheochromocytoma: the role of surgery. World J Surg. 1982; 06 (4) 397-402.

2. Jadvapour N, Woltering E, Brennan MF. Adrenal Neoplasm. Current Problems in Surgery, 1980; Jan.
3. Gagner M, Pomp A, Heniford B et al. Laparoscopic Adrenalectomy. Ann. Surg. Sep. 1997; 226:3.238-46.

4. Yu L, Fleckman A, Chadha M et al. Radiation Therapy of Metastatic Pheochromocytoma: Case Report. Am. Jou Clin Oncol, Aug, 1996; 19:4.389-93. 